\title{
The impact of climate change on water inflow of the three largest dams in the Beni Mellal-Khenifra region
}

\author{
Yousra El Baki $^{1 *}$, Khalid Boutoial $^{2}$, and Abdelouahid Medaghri-Alaoui ${ }^{3}$ \\ ${ }^{1}$ Faculty of Science and Technology, Sultan Moulay Slimane University, Marroco; \\ ${ }^{2}$ Higher School of Technology, Sultan Moulay Slimane University, Marroco; \\ ${ }^{3}$ Faculty of Science and Technology Sultan Moulay Slimane University, Marroco.
}

\begin{abstract}
Drought and water scarcity are resulting from the effects of climate change during recent decades. The region of Beni Mellal Khenifra, by the nature of its economic activities based particularly on agriculture and the availability of water resources, is considered among the most vulnerable regions to the effects of climate change in Morocco. In this paper, we analyzed the impact of climate change on the three largest dams in the region (Hassan first, Bin El Ouidane and Ahmed El Hansali), based on statistical data from five stations over 1990-2020. We used Normalized Precipitation Index (SPI) to characterize climatic drought, the Mann-Kendall test to assess the trend of temperature changes, Kendall's tau and linear regression to detect the relationship between climatic parameters (temperature and precipitation) and water supplies from the three dams. Standardized Precipitation Index (SPI) results showed that the region underwent a significant rainfall deficit between 1991- 1995, 2000-2003, 2005-2008, and 2017-2020. Their intensity varies from moderate to severe type. Moreover, temperature values obtained by Mann- Kendall test showed an increasing trend for all stations. Correlation analysis of rainfall and temperature with inflow dams showed that the mean annual inflows dams are directly proportional to the yearly average SPI increase.
\end{abstract}

\section{Introduction}

Global Warming is closely linked to contemporary lifestyles, production and consumption activities, which emit many greenhouse gases. Climate change affects all regions of the world. Outrageous weather occasions and precipitation are increasingly frequent in some areas, while others face increasingly extreme heat waves and droughts.

Water is at the core of these changes. The distinctive hydrological cycle segments are affected by climate change: modification of precipitation regimes, inundations, increase in sea level, desertification process, etc.

Precipitation in North Africa is expected to decrease by around $10-20 \%$, while temperatures increase to between 2 and $3{ }^{\circ} \mathrm{C}$ by 2050 [1]. In the arid and semi-arid zones of North Africa, particularly in Morocco [2] [3], the precariousness of water resources is not recent. In recent decades, the drought that has affected the countries of the Mediterranean basin has manifested itself severely and persistently, characterized by the remarkable intensity with dramatic consequences linked to significant quantitative and qualitative imbalances of water resources [4].

Beni Mellal Khenifra is one of the 12 regions of Morocco, portrayed by significant surface water and groundwater resources. While these water resources are threatened by the effects of climate change, which can affect both the annual water cycle and extremes such as flood, drought risks, and the seasonal distribution of rain.
The region has already experienced an increased rainfall that has impacted the inflows dams' deficit in recent years.

During the last years, the region of Beni MellalKhenifra underwent dry periods from 1980 to 1987, from 1991 to 1995 , from 1997 to 2002, and from 2006 to 2008, with different intensity levels from moderate to severe classes [5]. The standardized precipitation index is a popular index used to analyze the meteorological drought on a range of timescales. It was designed to quantify the precipitation deficit for multiple timescales. These timescales reflect the impacts of drought on different water resources needed by various decision-makers. Meteorological and soil moisture conditions (agriculture) respond to precipitation anomalies on relatively short timescales, for example, 1-6 months, whereas streamflow, reservoirs, and groundwater respond to longer-term precipitation anomalies of the order of 6 months up to 24 months or longer [6]. According to Zhim [5], the Oum ErRabia basin is highly vulnerable to drought, the duration and intensity vary considerably, and the most dominant type of droughts was moderate $(38 \%)$, while $15 \%$ was severe droughts. Moreover, between 1970 and 2010, the OER River basin tends towards drier conditions [7]. This research first aims to analyze rainfall variability, drought severity, and temperature trend over the period 1990-2020 in the Beni Mellal-Khenifra region, using Data from 6 stations and the largest tree dams in the area. Second, to study the correlation between rainfall, temperature variability, and water inflow of the tree dams chosen.

\footnotetext{
* Corresponding author: yousrabaq@gmail.com
} 


\section{Methods and data}

\subsection{Study years and area}

Beni Mellal-Khenifra Region includes dozens of dams and important transfer systems, allowing extensive landscape irrigation and providing drinking water not only for its population but also for neighbouring regions [8]. In this paper, we focused on the largest dams in the Béni Mellal-Khénifra region: Ahmed El Hansali (668.17 Mm3); Bin El Ouidane (1 215 Mm3); Hassan First; (236 Mm3) over the past thirty years 1990-2020.

\subsection{Data analysis}

The selection of rainfall stations was based on dams chosen, to obtain a large time series at least 30 years, with a minimum of missing and outliers data. All monthly rainfall and temperature data using in this study were collected from the Oum Er-Rabia hydraulic Basin Agency (ABHOER). Table 1 shows the locations of the stations chosen.

Table 1. Location of the stations used.

\begin{tabular}{c|cccc}
\multicolumn{1}{c}{ STATION } & $\mathbf{X}$ & $\mathbf{Y}$ & $\mathbf{Z}$ \\
\hline $\mathbf{1}$ & Tillouguite & 422670 & 158490 & 1100 \\
$\mathbf{2}$ & Ait Segumine & 361400 & 127950 & 1025 \\
$\mathbf{3}$ & Mechraa Eddahk & 394980 & 204800 & 425 \\
$\mathbf{4}$ & Ahmed El & 452750 & 231750 & 690 \\
& Hanssali & & & \\
$\mathbf{5}$ & Hassan First & 36500 & 137700 & 1125
\end{tabular}

\subsection{Standardized Precipitation index}

The SPI indicator developed by McKee and al. (1993) [9] and described in detail by Edwards and McKee (1997) [10] was designed to quantify the precipitation deficit at multiple time scales. These timescales reflect the impact of drought on the availability of different types of water resources. Soil moisture reacts relatively quickly to precipitation anomalies, while groundwater, streamflow, and volumes stored in reservoirs are sensitive to longerterm precipitation anomalies [6] [11].

McKee et al. (1993) used the classification system to define the severity of drought episodes from SPI values. They also set the criteria for a drought event for any time scale. A drought occurs when the index continuously shows a negative value of -10r less and ends when the index becomes positive.

This index is calculated by the following Equation:

$$
S P I=\frac{1}{N_{i}} \sum_{j=1}^{N_{i}} \frac{P_{j}^{i}-\overline{P_{J}}}{\sigma_{j}}
$$

With: $\boldsymbol{P} \boldsymbol{i}$ is the rainfall of the year i in the station j, $\overline{\boldsymbol{P}}$ average annual rainfall of the station $\mathrm{j}, \boldsymbol{N} \boldsymbol{i}$ the number of stations of the year $i$,
We calculated the SPI values using the SPI software program (SPI_SL_6.exe).

\subsection{Linear regression and Kendall's Tau}

We used Kendall's tau to analyze the correlation between rainfall and water dams, which indicates how strongly two variables are monotonously related. Linear regression was used to conclude the relationship between those two parameters. Indeed, we determined the regression equation and identified the characteristic parameters $\mathrm{r}, \mathrm{r} 2$, and $\mathrm{p}$ for these two stations. withe $r$ is the correlation coefficient, $r 2$ is the coefficient ofdetermination, and $\mathrm{p}$ is the risk of error $(0$ $<\mathrm{p}<\mathrm{r}$ ).

The software used is SPSS statistics.

\subsection{Mann-Kendall test and Sen's slope}

We used two non-parametric tests: Mann- Kendall (MK) test and Sen's slope estimator, to determine The annual and seasonal temperature trends for the period study chosen.

Sen's slope estimator is commonly used with the MK test; the two parameters are widely used in detecting trends of variables in meteorology and hydrology fields [12].

To determine the different parameters of these methods, we used the XLSTAT software.

\section{Results and discussion}

\subsection{Drought analysis}

The first analysis of rainfall data shows that the years 1994-1995, 1992-1993, and 1999-2000 recorded the lowest precipitation values, while 2009-2010, 19951996, and 2008- 2009 marked an increase in precipitation rates.

The standardized precipitations index (SPI) results revealed that $47,5 \%$ of months were dry for the Tillouguite station, 47,5\% for the Mechraa Eddahk station, and 50\% for the Hassan First station. The region underwent a significant rainfall deficit during 19911995, 2000-2003, 2005-2008, and 2017-2020, while the two periods of 1996-1998 and 2009-2014 were wet. These results confirm works conducted by [2-5].

To analyze the effect of the precipitation deficit on agricultural activities and water resources in the Béni Mellal-Khénifra region, we calculated the SPI values for the two-time scales 6 and 9 months between 1990 and 2020.

In total, the calculation of the SPI for the three stations shows 558 negative values and 572 positives values. Moreover, to identify the severity of the drought, we used the classification proposed by Mckee [9]. 


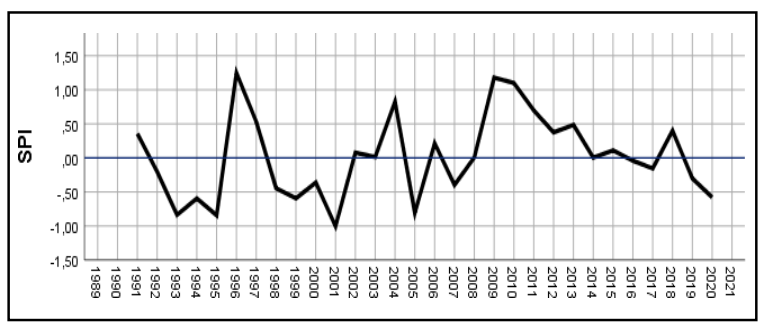

Fig. 1. Evolution of SPI in Beni Mellal Khenifra region during the period 1990-2020, at 6-month time scale.

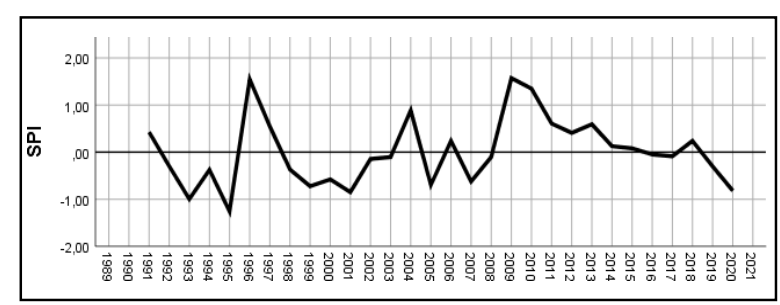

Fig. 2. Evolution of SPI in Beni Mellal Khenifra region during the period 1990-2020, at 9-month time scale.

Figures 1 and 2 show the evolution of the average SPI of the three stations for the time scale of 6 and 9 months. The minimum values obtained corresponding to the years: 1995, 1999, 2001, and 2020. At the same time, the minimum average value of all months corresponds to the year 1995 for the time scale of nine months and 2001 for six months.

In general, we obtained negative values of all average SPI values of the three stations in 1991-1995, 2000-2003, 2005-2008, and 2017-2020. The minimum values respectively in the three station (Tillouguite, Mechraa Eddahk, Hassan First) are: $(-2.89,-3,43,-1,82,-2,3)$ for nine months scale and $(-2,85,-3,01,-2,93,-1,85)$ for six months scale. Figures 3 and 4 show the evolution of the SPI of each station.
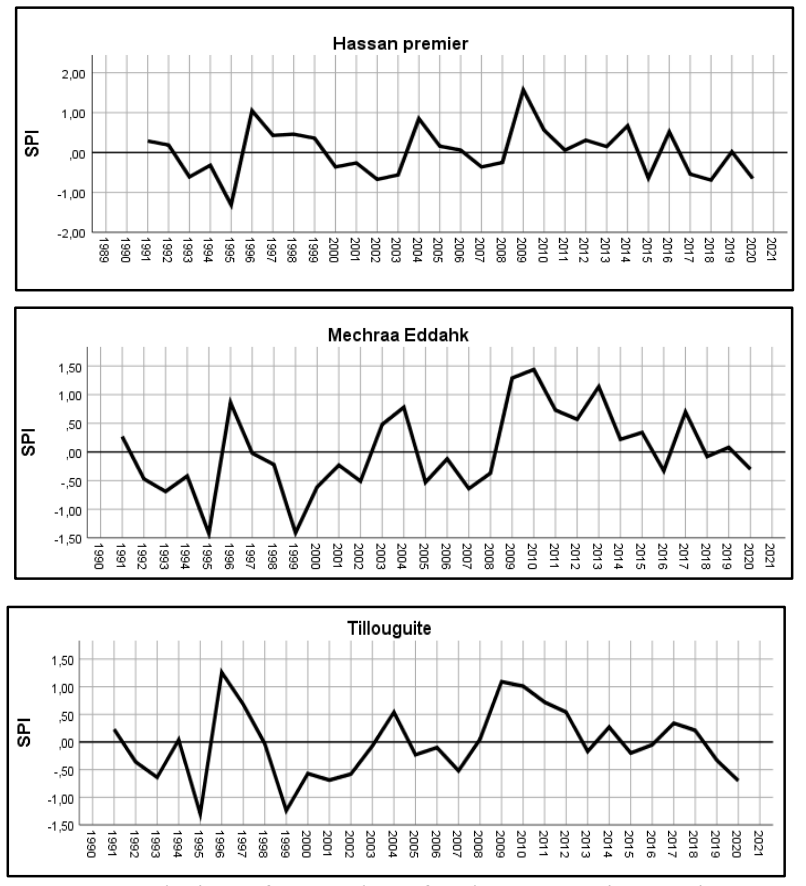

Fig. 3. Evolution of SPI values for the tree station at six months.

The comparison of the last time interval 2017-2020 with the other dry periods, we can deduce that the drought of the previous years from 2017 is less severe than the drought of last years, while after the dry period of 19911995, Béni Mellal-Khénifra region experienced significant rainfall between 1996-1998 and 2009-2013. After these two periods, the studied area experienced a deficit of precipitation compared to previous years. The SPI values do not exceed 1,69 for the three stations. Moreover, the highest SPIs values are those for the years 1996, 2009, and 2010. For the wet period of 2009-2013, we did not find any value for the dry classes: moderately dry, very dry, or extremely dry.
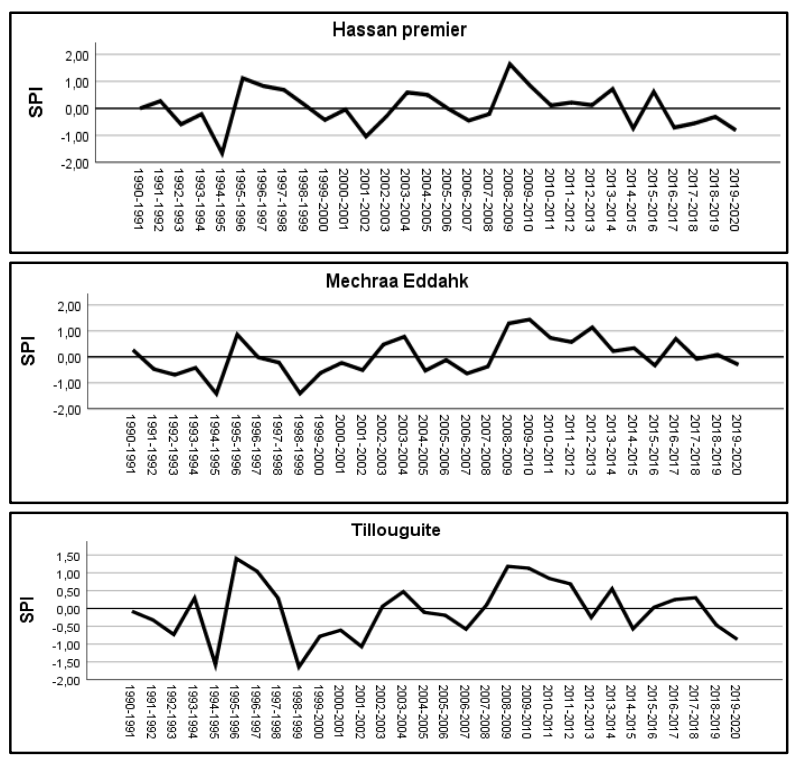

Fig. 4. Evolution of SPI values for the tree station at nine months.

After analyzing the total results of SPI obtained using the categorization proposed by [9] for the two-time scales, we found that the dominant class is: near the mild and moderate for dry classifications. Table 2 summarizes the result obtained.

Table 2. SPI results

\begin{tabular}{|c|c|c|c|c|c|c|c|c|}
\hline Class & 199 & 1995 & 2000 & 003 & $2005-2008$ & & 2017-2 & \\
\hline $\begin{array}{c}\text { Time } \\
\text { scales } \%\end{array}$ & 6 & 9 & 6 & 9 & 6 & 9 & 6 & 9 \\
\hline $\begin{array}{c}\text { Humid } \\
\%\end{array}$ & 7,8 & 1,4 & 2,8 & 4,2 & 3,4 & 1,4 & 10,8 & 8,3 \\
\hline $\begin{array}{c}\text { Near } \\
\text { to the } \\
\text { normal } \\
\%\end{array}$ & 61,2 & 60,1 & 75,6 & 73,1 & 80,6 & 80,1 & 71,8 & 77,5 \\
\hline Sec \% & 31 & 38,5 & 21,6 & 22,7 & 16 & 18,5 & 17,4 & 14,2 \\
\hline
\end{tabular}

The region has experienced significant agricultural and hydraulic drought over the four periods of 1992-1995, 2000-2003, 2005-2008, and 2017-2020. The higher number of dry months confirms the decrease of inflow dams in the region of Beni Mellal-Khenifra over the last years.

\subsection{Temperature Trend}

We employed The MK test and Sen's slope estimator with $95 \%$ confidence to assess the trend significance and 
magnitude of temperature data. Table 3 shows the results of the trend analysis.

The annual and seasonal temperature over the study period has shown an increasing trend for all stations.

All p-values are less than $\alpha$ value (0.05) expect the results of the Tillouguite station.

Table 3. SPI results

\begin{tabular}{|c|c|c|c|c|c|c|}
\hline Station & parameter & annual & Autumn & Winter & Spring & Summer \\
\hline \multirow{4}{*}{$\begin{array}{l}\text { Ahmd EI } \\
\text { anssali }\end{array}$} & $\begin{array}{l}\text { Sen's } \\
\text { slope }\end{array}$ & 0,068 & 0,087 & 0,207 & 0,075 & 0,103 \\
\hline & Kend tau & 0,377 & 0,32 & 0,072 & 0,372 & 0,342 \\
\hline & S & 153 & 129 & $\begin{array}{l}2 \\
9\end{array}$ & 151 & 138 \\
\hline & p-value & 0,004 & 0,016 & 0,599 & 0,005 & 0,01 \\
\hline \multirow{4}{*}{ Tillouguite } & $\begin{array}{l}\text { Sen's } \\
\text { slope }\end{array}$ & 0,028 & 0,042 & 0,052 & 0,052 & 0,009 \\
\hline & Kend tau & 0,301 & 0,238 & 0,233 & 0,233 & 0,076 \\
\hline & S & 131 & 103 & 101 & 101 & 33 \\
\hline & $\mathrm{p}$-value & 0,02 & 0,069 & 0,07 & 0,074 & 0,568 \\
\hline \multirow{4}{*}{$\begin{array}{l}\text { Ait } \\
\text { Segumine }\end{array}$} & $\begin{array}{l}\text { Sen's } \\
\text { slope }\end{array}$ & 0,215 & 0,248 & 0,24 & 0,0219 & 0,248 \\
\hline & Kend tau & 0,393 & 0,334 & 0,315 & 0,338 & 0,359 \\
\hline & S & 171 & 145 & 137 & 147 & 156 \\
\hline & $\mathrm{p}$-value & 0,002 & 0,01 & 0,015 & 0,009 & 0,006 \\
\hline
\end{tabular}

\section{3 analysis the effect of climate change on inflow dams}

To analyze the correlation between atmospheric parameters (temperature and precipitation) and inflow dams of Ahmad El Hanssali, Bin El Ouidane and Hassan First, we employed two methods: linear regression and Kendall-tau.

The correlation coefficient calculated by the two methods and the regression equations are summarized in Table 4. Findings indicate that the inflow dams have been affected positively by the deficit of precipitation.

Table 4. Regression parameters and equations

$\begin{array}{lcccc}\text { Dams/stations } & \text { Equation } & \mathbf{R 2} & \mathbf{R} & \boldsymbol{\alpha} \\ \begin{array}{l}\text { Bin El ouidane } \\ \text { Tillouguite }\end{array} & \mathrm{Y}=1,093 \mathrm{X}+169 & 0,797 & 0,893 & 0 \\ \begin{array}{l}\text { Ahmad El } \\ \text { Hanssali } \\ \text { Mechraa Eddahk }\end{array} & \mathrm{Y}=0,528 \mathrm{X}+211,7 & 0,759 & 0,871 & 0 \\ \begin{array}{l}\text { Hassan First } \\ \text { Hassan First }\end{array} & \mathrm{Y}=1,3 \mathrm{X}+235,4 & 0,669 & 0,818 & 0\end{array}$

Where $\mathrm{y}$ is the mean annual SPI, and $\mathrm{x}$ is the mean annual inflow dams.

As for Kendall's tau-b Table 5, the results show a strong correlation between the inflow dams and the annual SPI of the three stations and dams. Figure 6 illustrate clearly the correlation between the evolution of water inflows and the mean values of SPI for each station.
Table 5. Kendall's tau-b correlation coefficient

\begin{tabular}{|ccc|}
\hline Station & $\begin{array}{c}\text { Correlation } \\
\text { coefficient } \\
\text { Tillouguite }\end{array}$ & Sig \\
$\begin{array}{c}\text { Mchraa } \\
\text { Eddahk }\end{array}$ & 0,732 & 0 \\
$\begin{array}{c}\text { Hassan } \\
\text { First } \\
\text { Hassan } \\
\text { First }\end{array}$ & 0,609 & 0 \\
\hline
\end{tabular}
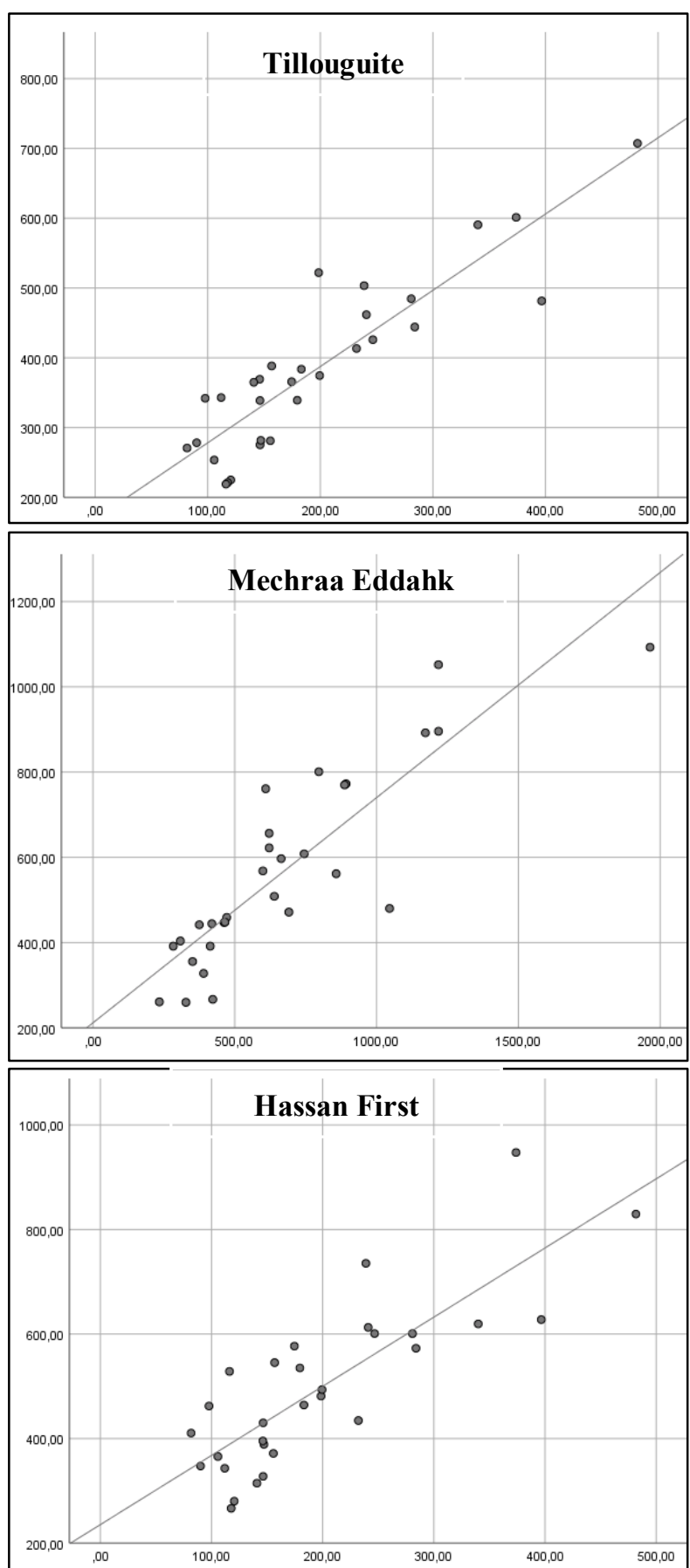

Fig. 5. Correlation of Rainfall and inflow dams

The results obtained in Figure 6 indicate that the mean annual inflow dams are directly proportional to the yearly average SPI increase, as the graph of the Mechraa Eddahk station clearly shows. However, in the wet period between 2012-2015, we notice that the SPI and dams inflow are not proportional for the other two stations. 
The two analytical correlation methods employed for temperature data showed no correlation between temperature variation and inflow dams. Indeed, the regression test for the average temperature and water inflow of the three dams showed a non-significant model with a low coefficient of 0,26 .

The two analytical correlation methods employed for temperature data showed no correlation between temperature variation and inflow dams. Indeed, the regression test for the average temperature and water inflow of the three dams showed a non-significant model with a low coefficient of 0,26 .

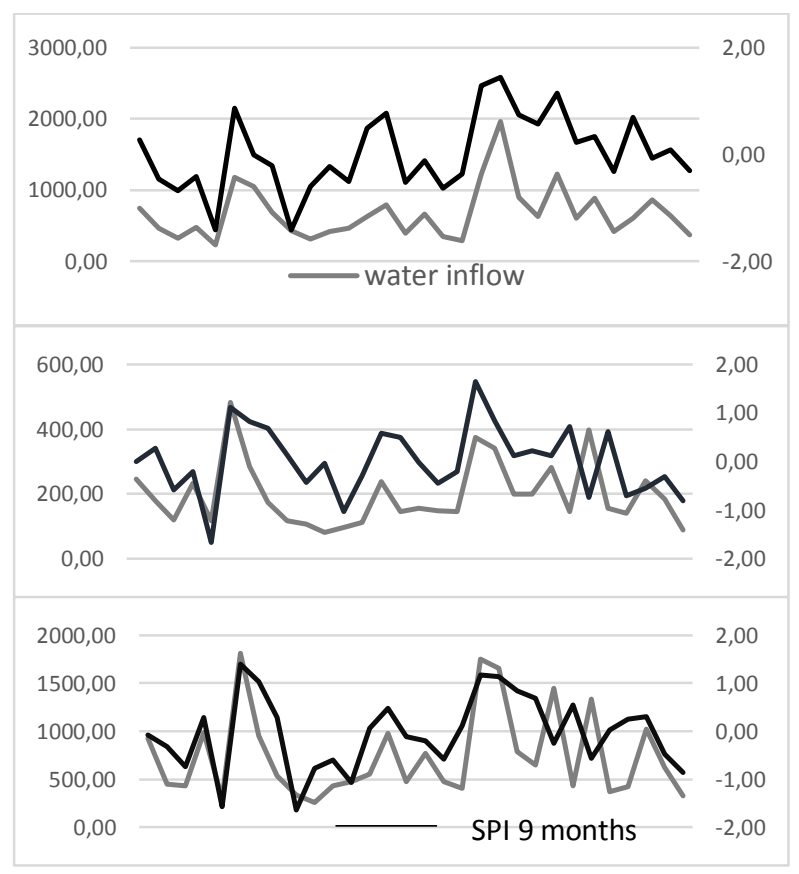

Fig. 6. Correlation The variation of average SPI and inflow dams between 1990 and 2020. a: Mechraa Eddahk station, b: Hassan first, c: Tillouguite.

\section{Conclusion}

In this paper, we chose the three largest dams in the region of Béni Mellal-Khénifra to study the impact of atmospheric parameters (temperature and precipitation) in regional surface water. We have used the standardized rainfall index to analyze the annual deficit and drought periods at two different time scales. Results obtained showed that the region underwent a significant rainfall deficit between 1991-1995, 2000-2003, 2005-2008, and 2017-2020, their intensity varies from moderate to severe type using the classification proposed by [9]. In contrast, the dominant drought category of SPI is medium.

Temperature data results obtained by Mann- Kendall test showed an increasing trend for all stations between the years 1990-2020 in the region of Beni MellalKhenifra.

Correlation analysis of rainfall and temperature with inflow dams showed that the temperature did not affect the water inflow of the tree dams during the study years. While The mean annual inflows dams are directly proportional to the yearly average SPI increase.
Agricultural activities in the region of Beni MellalKhenifra represent a fundamental pillar in the economic life of the population, hence the necessity of establishing good management and monitoring of regional water resources. Moreover, it is critical to mitigating climate change's impact by reducing economic and livelihood dependence on rain-fed agriculture, avoiding waterintensive crops and increasing the versatile capacity.

\section{ACKNOWLEDGEMENTS}

The authors would like to thank the Oum Er-Rbia agency, for providing rainfall, temperature and water inflow used in this paper.

\section{REFERENCES}

1. J. Schilling, P. Korbinian, E. Hertig, S. Jürgen Climate change, vulnerability and adaptation in North Africa with focus on Morocco, Agriculture, Ecosystems and Environment 156: 12-26. (2012)

2. Y. Daki, Z. Ghalem, R. Lachgar, H.El Hadi Caractérisation De La Sécheresse Climatique Du Bassin Versant D'oum Er Rbia (Maroc) Par Le Biais De L'indice De Précipitation Standardisé (SPI). European Scientific 12: 1857 - 7881 (2016).

3. L. Stour, A. Agoumi. Sécheresse climatique au Maroc durant les dernières décennies. Hydroécol. Appl 16: 215- 232 (2008).

4. A. Sebbar Etude de la variabilité et de L'évolution de la pluviométrie au Maroc (1935-2005):

Réactualisation de la carte des précipitations. These nationale, Université Hassan II Mohammedia Casablanca Faculté des Sciences Ben M'Sik Casa Blanca-Maroc (2013).

5. S. Zhim, A. Larabi, H.Brirhet Analysis of precipitation time series and regional drought assessment based on the standardized precipitation index in the Oum Er-Rbia basin (Morocco). Arab J Geosci 12:507 (2019).

6. Organization Standardized precipitation index user guide (2012).

7. H. Ouatik, A. Boudhar, A.Ouhinou, A.Arioua, Hssaisoune.M, Bouamri. H, Benabdelouahab.T (2019) Trend analysis of rainfall and drought over the Oum Er- Rbia River Basin in Morocco during 1970-2010. Arab J Geosci 12:128.

8. ABHOER (Agence du Bassin Hydraulique de l'Oum Er- Rbia) Update study of the master plan for integrated water resources development of the Oum Er Rbia hydraulic basin (2018).

9. Mckee TB, Doesken NJ, Kleist J (1993) The relationship of drought frequency and duration to time scales. Proc Intl Conf: Applied climatology. Anaheim, California.

10. Edwards, D, McKee. TB (1997) Characteristics of 20th-century drought in the United States at multiple time scales. Climatology Rep 97-2, Department of Atmospheric Science, Colorado State University, Fort Collins, Colorado.

11. EDO European drought observatory, Standardized Precipitation Index (SPI) (2020). 
https://edo.jrc.ec.europa.eu/

12. C. H. Bong and J. Richard. Drought and climate change assessment using Standardized Precipitation Index (SPI) for Sarawak River Basin. Water and Climate Change 11: 956-965 (2020). 